\title{
The Italian MV network dip performance characterization by contour charts as defined by UIE/CIGRE'/CIRED WG-C4.110
}

\author{
R. Chiumeo, C. Gandolfi, L. Garbero, L. Tenti \\ RSE- Ricerca Sul Sistema Energetico, \\ Via Rubattino 54 - 20134 Milano (Italy) \\ Phone/Fax number:+390239921, e-mail: Riccardo.Chiumeo@rse-web.it, Chiara.Gandolfi@rse-web.it, \\ Luciano.Garbero@rse-web.it, Liliana.Tenti@rse-web.it
}

\begin{abstract}
Reporting and analysis procedures play an important role in power quality monitoring systems especially for long term surveys. As far as voltage dips are concerned, the network voltage dip performance can be effectively described in many different ways depending on the aims of the data presentations at both site and system level.

The paper deals with network dip performance different representation methods focussing in particular on the way of presentation proposed by the working group UIE/CIGRE'/CIRED C4.110.

This method has been applied to the Italian 2009 voltage dips statistic as acquired by the Italian power quality monitoring system named QuEEN. Contour charts have been drawn for both different percentage of the monitoring sites and voltage dips types.
\end{abstract}

\section{Key words}

Power Quality, Network Voltage Dips performance, PQ Indices, Contour Charts, Percentile method.

\section{Introduction}

The Power Quality performance of a network is usually assessed by long term monitoring campaigns carried out on field, providing to have a proper number of monitoring sites which could be considered representative of the network itself. In this context the Italian MV network monitoring system named QuEEN (no less than 600 points of measurement, 400 of which installed in primary substations [1], [2]) has been collected power quality data since February 2006 providing a lot of power quality data to represent the network performance.

As far as voltage dips are concerned, the network voltage dip performance can be effectively described in many different ways at both site and system level, that is, in the last case, referring to all the monitored sites at once.

Starting from the presentation of simple voltage dips tables, the network voltage dips performance can be represented in a more synthetic way by a set of single system indices or in graphical forms as simple isonumerousness curves maps or, finally, by the dip coordination charts proposed by the working group UIE/CIGRE'/CIRED C4.110 [3], [4].

The adoption of the last one kind of presentation should enable the estimation of the number of end-user equipment malfunctions due to voltage dips providing to known the voltage dips characteristic typical of a network and end-user equipment response to dips in the form of, so called, equipments immunity curves.

The coordination charts, presented hereafter, are based on the voltage dips data acquired by the Italian monitoring system QuEEN in 2009 at the 400 measurements sites placed in a same number of primary substations. The monitored sites can be considered representative of the Italian MV distribution network (about the $11 \%$ of the total amount of MV bus-bars). An example of application of dip coordination chart is presented.

This activity has been carried out by RSE - Ricerca sul Sistema Energetico, in the frame of the Research Fund for the Italian Electrical System, and regards tasks focused on power quality.

\section{Voltage dip performance presentation methods}

A certain number of network voltage dip performance presentation methods have already been proposed at international level at both site and system level depending on the statistical aspects to which one is going to pay attention.

A typical representation method of voltage dips statistic consists in classifying the events, monitored during a survey period, in tables on the base of their duration and residual voltage, providing for each events class its numerousness at site level or other statistical quantity as the $95 \%$ percentile.

Referring to this representation method (named in the following as tabular method), the new edition of the standard EN 50160 Ed. 2010 proposes a voltage dips classification strongly related to the immunity curves for class 2 or class 3 equipments, as they have been defined 
on the base of the equipment test levels mentioned by the standard IEC 61000-4-11 and IEC 61000-4-34 [5], [6].

Besides the network voltage dips performance can be represented in a more synthetic way by a set of single system indices closely related to the network voltage dips performance level. This method is particular suitable to make comparisons among the voltage dip performances of different parts of a network, or to investigate a network historical trend in term of assured power quality level [7]. In particular, at first, simple counting indices, associated to the events which lay below a given immunity curve, can be evaluated together with other more refined indices which can weight, in some way, the single characteristics of the events (duration and residual voltage) with respect to a given immunity curve.
Other graphical methods of representation of the voltage dips performance have surely a stronger visual impact on users. This is the case of the voltage dips isonumerousness curves (curves connecting points characterized by the same number of dips per year) on the residual voltage vs. duration plane (Fig. 1). These curves are particularly suitable to highlight the events concentration in those plane areas related to the intervention characteristics of the network protection system. The map in Fig. 1 shows distinctly two voltage dips concentration areas characterized by different durations of the events (the first in the range $20 \div 150 \mathrm{~ms}$ the second in the range $300 \div 350 \mathrm{~ms}$ ) which are consistent with the behaviour of network protections at MV level.

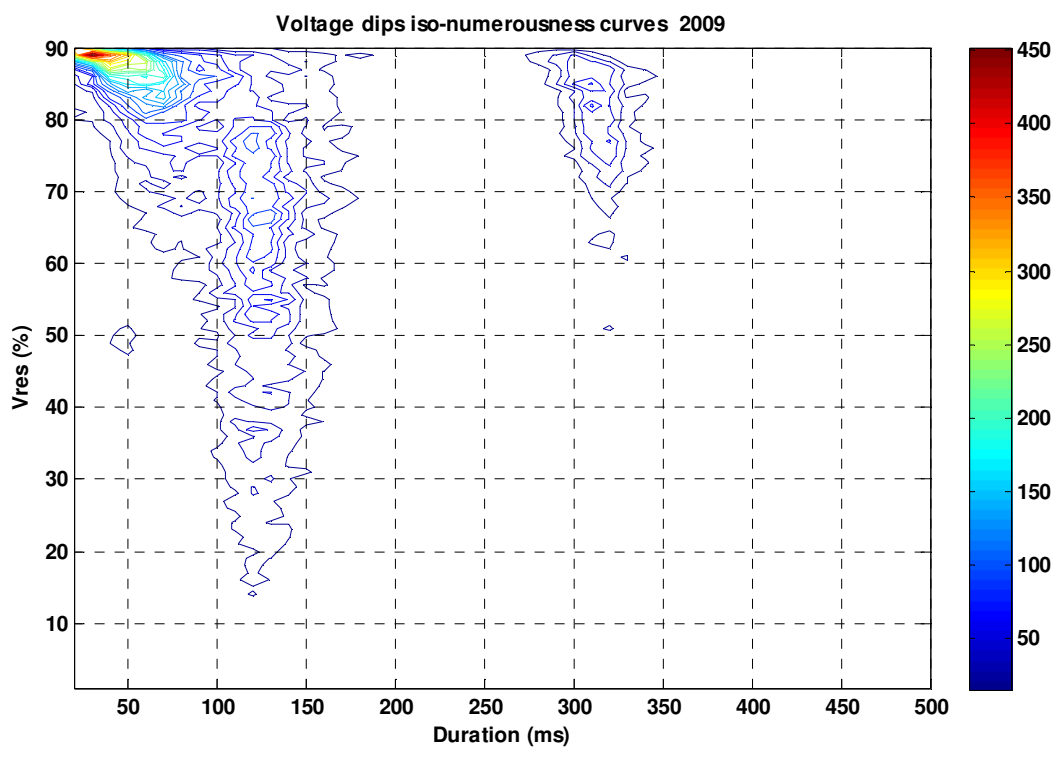

Fig. 1. Iso-numerousness curves map related to the 2009 voltage dips statistic for the MV network

\section{The UIE/CIGRE'/CIRED WG-C4.110 dip coordination charts}

A more complex graphical representation of the network voltage dip performance is that developed in the frame of the working group UIE/CIGRE'/CIRED C4.110 activity.

In this context the voltage dips statistic is presented by a peculiar type of contour charts: usually contour charts are graphical representation of a two dimensional function of the residual voltage $\mathrm{V}$ and of the duration $\mathrm{t}$ of the dip.

In this kind of charts the function values are the numbers of voltage dips per year with duration longer than $t$ and a residual voltage less than $V$ not exceeded by a defined percentage of the sites. In fact the method can be applied both to a single site and to a sample of sites representative of a network (percentile approach).

In Fig. 2, the 95\% percentile approach has been applied to the voltage dips monitored by the QuEEN system in 2009: the red dot, for example, identified 15 events/year with features more severe than $(\mathrm{t}, \mathrm{V})$.

The chart has been realized by the 3 steps procedure suggested by the international WG in [3] adopting a resolution of respectively $10 \%$ of voltage and $50 \mathrm{~ms}$ of duration.

In other words these charts are able to represent the network dip performance by the number of events, with definite characteristics, which are never overcome in a site or in different percentage of monitored sites. 


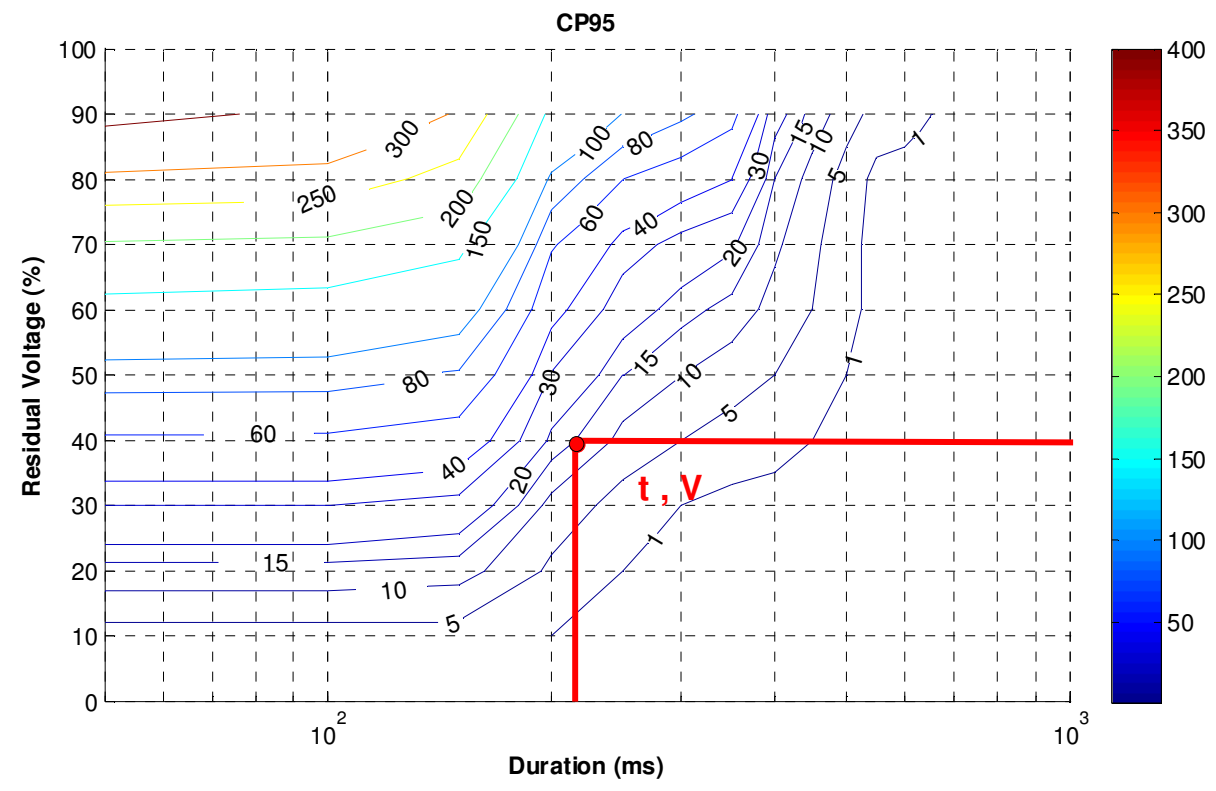

Fig. 2. Contour charts for the MV 95\% best sites monitored in 2009

\section{The application of the contour charts method to the Italian voltage dips data}

To represent the variation between sites in the Italian MV network, the voltage dips contour charts style WGC4.110 have been extended also to the $50 \%$ and $25 \%$ of the sites of the Italian monitoring system (Fig. 3).

As the QuEEN system measures the three line to line voltages, the voltage dips features used to draw the charts have been measured, in accordance with the standard IEC-61000-4-30 [8] in the following way:

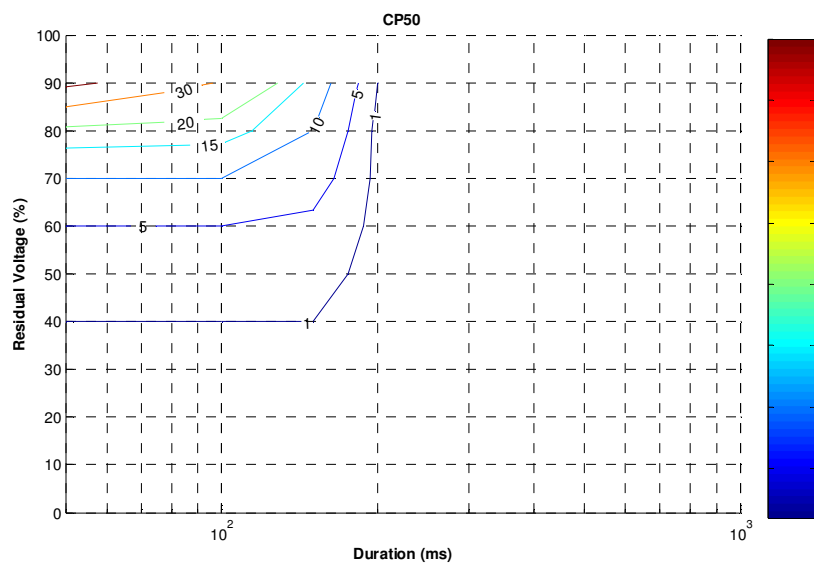

- the residual voltage is the lowest $\mathrm{U}_{\mathrm{rms}(1 / 2)}$ value measured on any channel during the dip;

- the duration is the time difference between the beginning and the end of the voltage dip and, for polyphase measurements, can be started on one channel and terminated on a different channel.

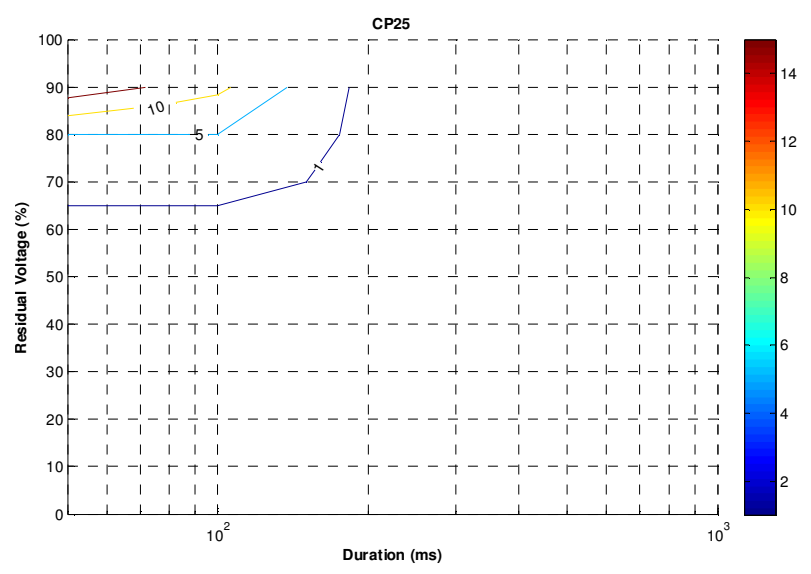

Fig. 3. Contour charts for the MV 50\% (on the left) and the $25 \%$ (on the right) best sites monitored

Considering that the voltage dip effects on the equipments are closely linked to voltage dips types (balanced or unbalanced events), contour charts have been drawn for different types of voltage dips involving respectively three, two or only one line to line voltages for the $95 \%$ of the sites (see Fig. 4, Fig. 5 and Fig. 6).
Referring to the last chart it can be observed that there is a remarkable increase in residual voltage for this type of events together with a decrease of their numerousness. 


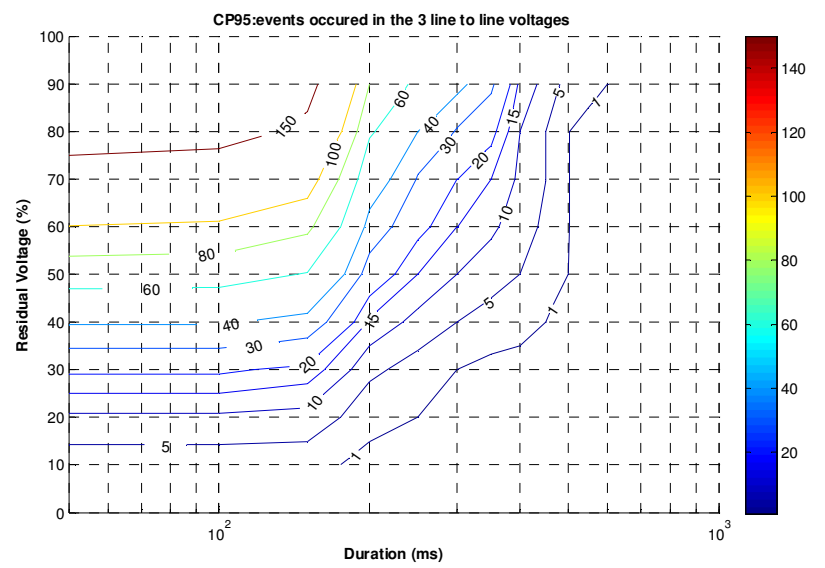

Fig. 4. Contour charts for the $95 \%$ of best sites for events occurring in the 3 line to line voltages

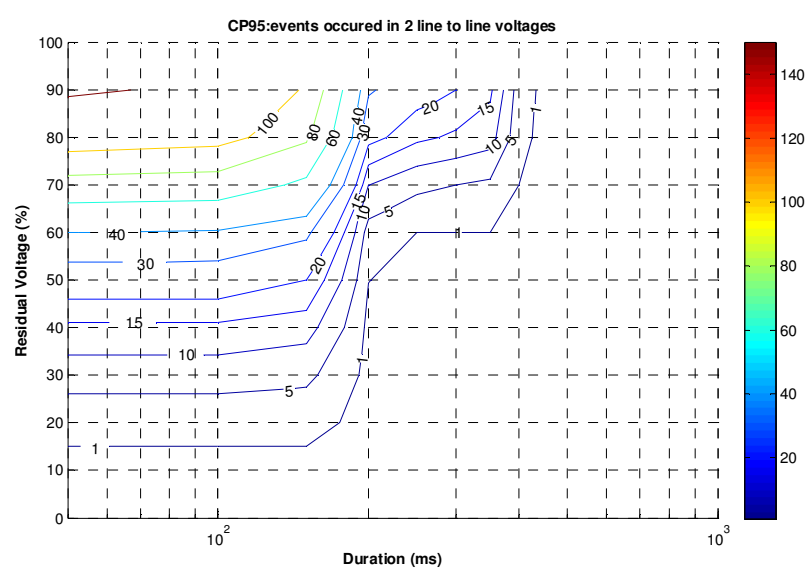

Fig. 5. Contour charts for the $95 \%$ of best sites for events occurring in 2 line to line voltages

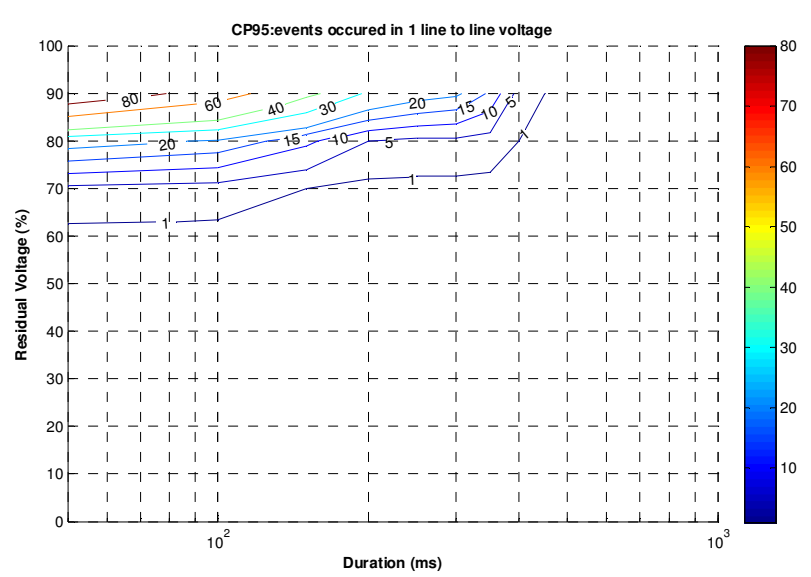

Fig. 6. Contour charts for the $95 \%$ of best sites for events occuring only in one of the 3 line to line voltages

\section{The contour charts vs. the immunity curves}

In order to coordinate both the supply and the equipment performances, the voltage dip contour charts can be compared with the equipment immunity curves [3].

As an example, two rectangular immunity curves named "1" and " 2 " have been taken into account to be compared with the abovementioned contour charts, relevant to the Italian network dip performance. Rectangular immunity curves are typical of electronic apparatus and, in this example, we consider two kind of equipments belonging to the same process and related to the two immunity curves (Fig. 7).

In fact, starting from both the contours chart for the $95 \%$ of sites and the immunity curve for the equipment, it is possible to evaluate the maximum number of voltage dips which could be responsible for the process malfunctioning. Referring in particular to Fig. 7, the equipments associates to the rectangular immunity curves " 1 " and " 2 " could be subjected in a year at a maximum of, respectively, 60 and 10 potentially "dangerous events" in the $95 \%$ of the sites.

In the case of the presence in a same process of both types of equipments it is possible to evaluate the maximum number of "dangerous events" for it by applying the following procedure:

- the identification of the areas which characterized the possible malfunctioning zone (A, B and $\mathrm{C}$ );

- the evaluation of the maximum number of events expected in a year, for these areas, by solving the following system:

$$
\left\{\begin{array}{l}
60=A+B \\
10=B+C \\
5=B
\end{array}\right.
$$

In this example, the maximum number of events in a year, which could cause a process malfunctioning (Nev), can be evaluated as:

obtaining

$$
\mathrm{A}+\mathrm{B}+\mathrm{C}
$$

$\mathrm{Nev} \leq 65$ event/year.

The countors curves, indicative of the network dip performance, could be used to evaluate the maximum number of events expected in a year in the $95 \%$ (or other percentage) of the sites also to specify the apparatus immunity requirements and, at last, their design. 


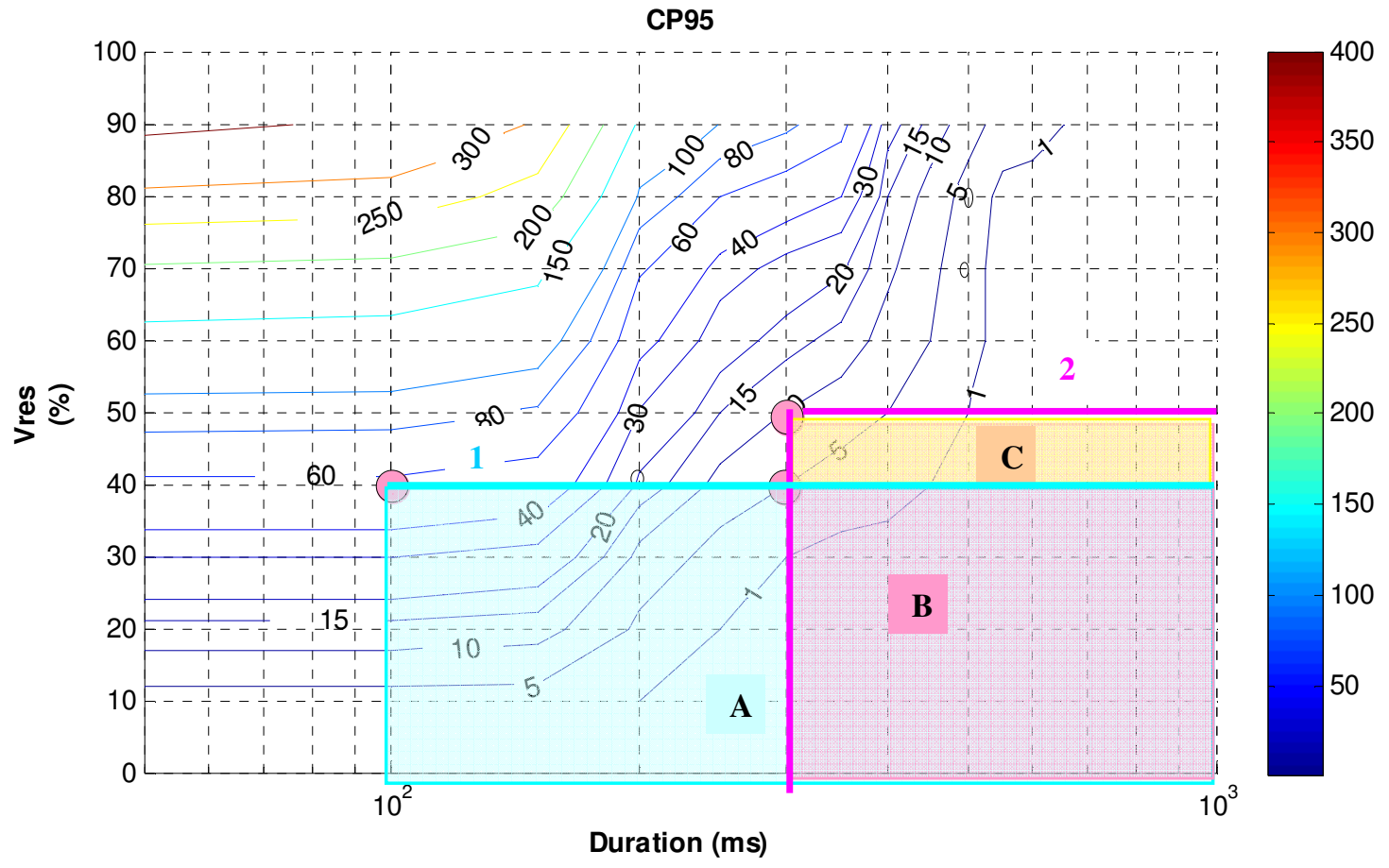

Fig. 7. Correlation between the voltage dip performance of the $95 \%$ of sites with the immunity curves " 1 " and " 2 "

\section{Conclusions}

The voltage dips performance reporting method proposed at international level by the UIE/CIGRE'/CIRED C4.110 working group has been applied on the voltage dips data acquired in 2009 by the Italian MV monitoring system QuEEN.

This method should allow coordinating the supply and the equipment performances by comparing the voltage dip contour charts with the equipment immunity curves. At present, this comparison has been applied to two rectangular immunity curves.

In the future, the comparison could be extended to other more complex immunity curves taking into account also the voltage dip performance monitored at plant level by a few customers who took part to the monitoring campaign in the past.

\section{Acknowledgement}

This work has been financed by the Research Fund for the Italian Electrical System under the Contract Agreement between RSE (formerly known as ERSE) and the Ministry of Economic Development - General Directorate for Nuclear Energy, Renewable Energy and Energy Efficiency stipulated on July $29^{\text {th }}, 2009$ in compliance with the Decree of March $19^{\text {th }}, 2009$.

\section{References}

[1] F. Villa, A. Porrino, R. Chiumeo, S. Malgarotti, "The power quality monitoring of the MV network promoted by the Italian regulator", $19^{\text {th }}$ International Conference on Electricity Distribution, CIRED, Vienna 2007, Paper 0042.

[2] R. Chiumeo, A. Porrino, L. Garbero, L. Tenti, M. de Nigris, "The Italian Power Quality Monitoring System Of The MV Network: Results Of The Measurements Of Voltage Dips After 3 Years Campaign", $20^{\text {th }}$ International Conference on Electricity Distribution, CIRED, Prague 2009, paper 0737.

[3] CIGRE/CIRED/UIE Joint Working Group C4.110 "Voltage Dip Immunity of Equipment and Installations", Report $N^{\circ} 412$, April 2010.

[4] M. Bollen, J.R. Gordon, S. Djokic, K. Stockman, J. Milanovic, R. Neumann, G. Ethier, "Voltage-dip immunity: statistics and need for further work", ICREPQ, Granada, Spain, 2010, Paper 312.

[5] IEC 61000-4-11: Testing and measurement techniques Voltage dips, short interruptions and voltage variations immunity tests.

[6] IEC 61000-4-34: Testing and measurement techniques Voltage dips, short interruptions and voltage variations immunity tests for equipment with input current more than 16 A per phase.

[7] R. Chiumeo, M. de Nigris, C. Gandolfi, L. Garbero, L. Tenti, "Voltage dips performance characterization by PQ indices at national and macro area level", $14^{\text {th }}$ International Conference on Harmonics and Quality of Power, ICHQP, Bergamo 2010, Paper 93.

[8] IEC 61000-4-30: Testing and measurement techniques Power quality measurement methods. 